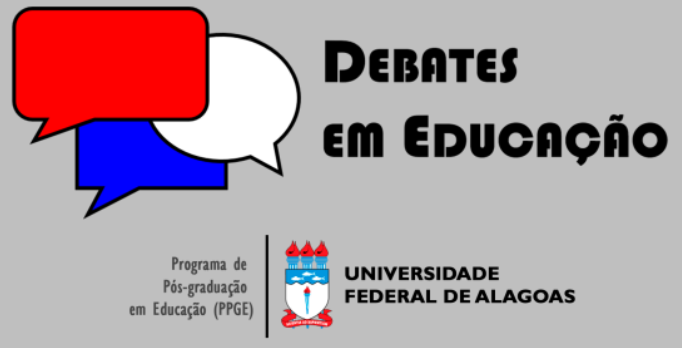

ISSN Eletrônico 2175-6600

Vol. 12 | Número Especial | 2020

Aline Renata dos Santos

(9) iD

Universidade Federal de Pernambuco (UFPE) aline.renata24@hotmail.com

Janssen Felipe da Silva

(5) iD

Universidade Federal de Pernambuco (UFPE) janssenfelipe@hotmail.com

\section{CURRÍCULO PÓS-COLONIAL E PRÁTICAS DOCENTES DESCOLONIAIS: CAMINHOS POSSÍVEIS}

\section{RESUMO}

presente texto trata sobre práticas docentes descoloniais através do currículo póscolonial. Pressupomos que os currículos escolares ainda permanecem, predominantemente, sob os ditames coloniais e que as práticas docentes são espaçotempo da diferença colonial tensionadas por movimentos de colonização e de descolonização. Utilizamos a pesquisa bibliográfica e a análise de conteúdo para apresentarmos elementos do currículo pós-colonial e das práticas docentes descoloniais. Concluímos que práticas docentes descoloniais são possíveis através de dois movimentos, a saber: desvendar as heranças coloniais nos currículos e construir práticas outras que rompam com o cânone eurocêntrico, valorizando os conhecimentos dos sujeitos que, historicamente, foram silenciados e negados pelo referido cânone.

Palavras-chave: Currículo Pós-Colonial. Práticas Docentes Descoloniais. Professores/as/ decisores/as curriculares.

\section{POST-COLONIAL CURRICULUM AND DECOLONIAL TEACHING PRACTICES: POSSIBLE WAYS}

\begin{abstract}
This text deals with decolonial teaching practices through the post-colonial curriculum. We assume that school curricula still remain, predominantly, under colonial dictates and that teaching practices are space-time of colonial difference tensioned by colonization and decolonization movements. We use bibliographic research and content analysis to present elements of the post-colonial curriculum and decolonial teaching practices. We conclude that decolonial teaching practices are possible through two movements, namely: unveiling colonial inheritances in the curricula and building other practices that break with the Eurocentric canon, valuing the knowledge of the subjects who, historically, have been silenced and denied by that canon.
\end{abstract}

Keywords: Postcolonial Curriculum. Decolonial Teaching Practices. Curricular decision makers teachers.

Submetido em: 03/03/2020

Aceito em: 20/05/2020

Publicado em: 10/12/2020

dof http://dx.doi.org// 0.28998/2175-6600.2020v I 2nEspp387-407 


\section{INTRODUÇÃO}

O presente texto faz parte de uma pesquisa de doutorado, em andamento, no programa de pósgraduação em educação da Universidade Federal de Pernambuco e trata de práticas docentes descoloniais a partir da perspectiva teórica de currículo pós-colonial. Pressupomos que os currículos escolares ainda permanecem, predominantemente, sob os ditames coloniais e que as práticas docentes são espaçotempo da diferença colonial (MIGNOLO, 20II) tensionadas por movimentos de descolonização na proposição e na construção de currículos/práticas descoloniais. Almeida e Silva (20 I 5) compreendem que a diferença colonial é locus de disputa em que podem ser gestadas condições de prosseguimentos de diálogos. Tais diálogos produzem formas outras ${ }^{1}$ de pensar constituídas pelo conhecimento eurocêntrico e pelos conhecimentos outros, construindo epistemologias outras no seio da diferença colonial e do pensamento de fronteira.

Nessa compreensão, as práticas docentes localizam-se no limiar da diferença colonial, melhor dizendo, nas tensões provocadas pelos direcionamentos das políticas educacionais, entre elas aquelas curriculares, a exemplo da Base Nacional Comum Curricular e do Programa Nacional do Livro Didático, frente às práticas de resistências, aceitações e adequações protagonizadas pelos/as docentes no cotidiano das salas de aulas.

As práticas docentes são espaço-tempo de negociações, resistências e aceitações influenciadas por contextos sociais, culturais, políticos nos quais os sujeitos estão inseridos. A prática docente, nesse entendimento, não se restringe à simples repetição das políticas educacionais, mas é também resultado dos diversos contextos, sujeitos, crenças, valores, teorias com as quais professores/as se identificam e abraçam para compor a sua prática nas redes cotidianas que são constituídas por contradições, ambivalências e assimetrias.

Diante do exposto, com este artigo, objetivamos entender as práticas docentes enquanto um dos espaços-tempo de possibilidades de descolonização dos currículos. Assim, professores/as são peças fundantes para construir e materializar essas práticas, pois são protagonistas no processo de decisão curricular no cotidiano escolar, seja para aceitar, seja para subverter, adaptar e/ou transformar os currículos, descolonizando-os ou ainda, ambivalentemente, contradizendo e afirmando o currículo prescrito ao mesmo tempo

Diante desse entendimento, professores/as, enquanto intelectuais críticos (APPLE, 2017), mobilizam seus fazeres (FREIRE, 1987) nas contradições do cotidiano escolar e, portanto, não estão alheios/as aos processos de recontextualização (BERNSTEIN, 2003) curricular. Logo, professores/as são

\footnotetext{
' $\bigcirc$ termo outras/os diz respeito a um entendimento daquilo que está fora, negado ou silenciado pelo cânone eurocêntrico.
} 
decisores curriculares (LEITE, 2006) e um dos espaços de decisão e de recontextualização curricular é o cotidiano da sala de aula, na consolidação das práticas docentes.

Nessa direção, é importante frisar que a prática docente não se faz apartada das práticas curriculares, visto que são "espaço de criação curricular e não apenas como momentos de aplicação de currículos pré-fabricados" (OLIVEIRA, 2005, p. 232). Tal como a prática curricular, a prática docente constitui-se enquanto espaço de criação de currículo. Apesar das diversas tentativas de reduzir o papel dos professores/as a meros/as executores/as de decisões verticalizadas, prescritas por outros afastados do contexto do cotidiano escolar, eles/as revelam possibilidades outras de construção e reinvenção curricular, caminhando para uma possível descolonização dos currículos e das práticas docentes.

A perspectiva teórica de currículo adotada desvela as amarras imperiais-neocolonialistas que ainda fundamentam e colonizam os currículos escolares. Igualmente, provocam aberturas políticas e epistemológicas na construção e no desenvolvimento de currículos outros. A teoria de currículo póscolonial abre um campo fértil para a construção de práticas docentes descoloniais e isso não ocorre sem embates e conflitos, uma vez que essas práticas acontecem na arena de disputas dos contextos de influência, de produção de texto e no contexto da prática (BALL, 200 I) reverberando no cotidiano escolar.

No intuito de cumprir com o objetivo do texto, realizamos uma pesquisa bibliográfica e utilizamos a análise de conteúdo via análise temática (BARDIN, 201 I; VALA, 1990), que nos ofereceram subsídios para a organização dos dados e escrita interpretativa deste trabalho. Para tanto, seguimos as fases de desenvolvimento da análise de conteúdo: pré-análise; exploração do material; tratamento e inferências. Na pré-análise reunimos os textos que julgamos ser representativos para darem respostas ao objetivo do artigo, tal como podem ser observados nas referências. Na fase de exploração do material selecionamos os conceitos que nos ajudaram a pensar em uma prática docente descolonial, ancorada na perspectiva de currículo pós-colonial, particularmente: colonialismo; interculturalidade; interepistemologia; pensamento de fronteira; ecologia de saberes; diferença colonial; identidade na política; sujeitos curriculares outros; decisores curriculares; prática docente; prática docente descolonial. Por fim, no tratamento e inferências, construímos uma rede de significados que nos indicaram possíveis caminhos para uma prática docente descolonial, conforme apresentaremos nas seções que compõem o artigo.

A título de organização, o artigo foi dividido em três seções, além da presente introdução e referências bibliográficas. A primeira seção aborda o currículo pós-colonial, enfatizando sua definição, seus objetivos e proposições curriculares. No tocante à segunda seção, ela se refere à discussão sobre a constituição de uma possível prática docente descolonial. Por fim, finalizamos o texto, destacando as principais conclusões as quais chegamos. 


\section{CURRÍCULO PÓS-COLONIAL: RUPTURAS POLÍTICO-EPISTÊMICAS COM O CÂNONE EURONORTECÊNTRICO}

Nesta seção, abordaremos a perspectiva do currículo pós-colonial, enfatizando o seu lugar dentro das teorias curriculares e os elementos basilares que o constituem sendo eles: interculturalidade; interepistemologia; pensamento de fronteira; ecologia de saberes; diferença colonial; identidade na política; sujeitos curriculares outros. Por fim, abordamos a intencionalidade do currículo pós-colonial que é a de contribuir na superação da sociedade patriarcal/racista/colonial/capitalista/moderna, tendo como alicerces a educação intercultural e a pedagogia decolonial.

O currículo pós-colonial, conforme Lopes (2013) e Silva (2010), insere-se na teoria pós-crítica de currículo juntamente com os estudos pós-modernistas, pós-estruturalistas, pós-fundacionais, pós-marxistas e estudos culturais. De acordo com Lopes (2013), o termo teorias pós-críticas é empregado para interpelar os pressupostos das teorias críticas influenciadas pelo marxismo da Escola de Frankfurt e, de alguma maneira, da fenomenologia.

Para a autora, na perspectiva crítica, geralmente, determina-se uma cronologia da história do pensamento curricular, parte-se da ideia de que o currículo passou por uma evolução, tendo como ponto de partida as teorias tradicionais e sendo superado pelas teorias críticas para, então, avançar em direção às teorias pós-criticas. No intuito de romper com a linearidade desse gradualismo, Lopes (20।3) utiliza-se do hibridismo (HALL, 2003) entendido enquanto um momento ambíguo de coexistências de relações de poder ambivalentes e assimétricas, decorrentes dos distintos sujeitos, contextos históricos, políticos, sociais, culturais. Intenciona, assim, compreender elementos característicos das distintas teorias curriculares coexistindo.

Seguindo essa linha de pensamento, compreendemos que as teorias: tradicional (colonial), crítica e pós-critica convivem em constantes disputas nos diversos contextos, isto é na formulação das políticas curriculares; no espaço escolar; nas práticas curriculares, nos livros didáticos, etc. Essa coexistência, evidentemente, não é harmônica, já que o campo do currículo é tensionado por forças que disputam o lugar da hegemonia curricular, provocando movimentos de assimetrias e ambivalências. Embora concordemos com a ideia de hibridismo, as teorias, sejam elas tradicionais, críticas e pós-críticas possuem singularidades que as aproximam e as distanciam.

No caso das teorias pós-críticas, elas partilham de um leque de conceitos que permite rupturas com as teorias tradicional e crítica. Logo, as teorias pós-críticas ampliam o conjunto conceitual para compreender o currículo a partir de outros olhares. Assim, tomam os conceitos de identidade, alteridade, diferença, subjetividade, significação, discurso, saber-poder, representação, cultura, gênero, raça, etnia, 
sexualidade e multiculturalismo (SILVA, 20I0), enquanto foco de contestação, análise, compreensão e proposição curricular.

Embora compartilhem desses conceitos, as teorias pós-críticas possuem diferenças que as particularizam haja vista que possuem questões próprias para área das humanidades e, especificamente, para a educação e para o currículo. Não é objetivo desse trabalho elencar semelhanças e diferenças de cada perspectiva, mas de apresentar e aprofundar o olhar a respeito da perspectiva pós-colonial de currículo, visto que nos filiamos a ela para pensar e construir currículos descoloniais que rompam com currículos colonizadores (GOMES, 2012).

Na perspectiva teórica do currículo pós-colonial, a preocupação centra-se em compreender as relações de poder estabelecidas pelos colonizadores nos países que passaram por processos de colonialismos (SILVA, 20I0) herdados pelos currículos escolares. $O$ colonialismo é aqui apreendido enquanto uma nova ordem de poder direta e formal imposta aos povos "descobertos" nas terras do "novo mundo" e daqueles que, mais tarde, foram trazidos como escravos de diversas regiões da África (QUIJANO, 2005). Trata-se, portanto, do estabelecimento de relações políticas, econômicas desiguais entre nações tidas como superiores (espanhóis e portugueses) e nações vistas como inferiores, povos originários, por exemplo: Aztecas, Mayas, Chimús, Aymaras, Incas, etc. e os escravizados do continente africano: Angolas, Mondongos, Congos, Yolofos, Minas, etc. (SANTOS, 2017).

A consolidação do colonialismo tomou como lastro duas pilastras fundamentais: a racionalização e a racialização (QUIJANO, 2005). A primeira diz respeito à hegemonia dos conhecimentos produzidos pelos europeus e às formas de produção, sendo considerados os únicos detentores e legitimadores de epistemologias válidas, estabelecendo-se como referência para determinar o que é e o que não é conhecimento.

Por conseguinte, os conhecimentos dos povos originários e dos povos escravizados advindos da África foram deslegitimados, pois suas formas de produzir conhecimento não foram consideradas visto divergirem do estabelecido como referência de produção de conhecimento pelos colonizadores. Conforme Almeida e Silva (2015. p. 52), "a epistemologia moderna produziu não só uma forma de construir conhecimentos, mas promoveu modos de vida; estabeleceu o que era certo ou errado, definiu formas, conteúdos e valores para a vida cotidiana dos povos colonizados".

Essas definições e demarcações desconsideraram as cosmovisões dos povos originários e dos afrodiaspóricos, resultando em epistemicídios (SANTOS; MENESES, 2010a) que são as tentativas de aniquilação e/ou inferiorização dos conhecimentos outros pertencentes a esses sujeitos, ocultando a riqueza presente nas multifacetadas cosmovisões que produzem pluralismos epistemológicos.

Os rebatimentos nos currículos escolares pilastra da racionalização estão presentes, dentre outros, nos materiais didáticos curriculares/pedagógicos, como os livros didáticos e paradidáticos que ainda 
celebram a racionalidade eurocêntrica como referência de desenvolvimento e de conhecimento válido. Arroyo destaca que

com o culto às cidades se decreta o desaparecimento do campo. Com o culto à industrialização se decreta o desaparecimento de outras formas de produção como ultrapassadas. Com o culto ao progresso científico e ao futuro se decreta o desaparecimento dos saberes ancestrais, da tradição e se apagam as vivências do passado e do presente. $\bigcirc$ mais grave é que se decreta o desaparecimento dos coletivos humanos que estão atolados nas vivências do presente e em formas de produção da existência supostamente pertencentes ao passado (20l I, p. 263).

A pilastra da racionalização demarca o que é valido de ser aprendido produzindo a exclusão dos conhecimentos que destoam da racionalidade moderna. Por isso são criadas classificações e hierarquizações para garantir que a pretensa hegemonia da razão moderna eurocêntrica se sobressaia às racionalidades outras, como é o caso dos povos do campo versus povos da cidade, dos homens/mulheres, das mulheres brancas/mulheres negras/indígenas/ciganas, dos homens brancos/homens negros/indígenas/ciganos, etc. (SARTORE; SANTOS; SILVA, 20I 5). Para o sucesso dessa pilastra, operouse um convencimento dos sujeitos outros de sua irracionalidade devido a sua pertença racial, étnica, territorial, a imbricação da racionalização com a racialização torna-se um importante elemento de convencimento dos sujeitos outros de sua "inferioridade".

Desse modo, a segunda pilastra, da racialização, dar-se com a construção mental da ideia de raça que classifica e hierarquiza os povos superiores e inferiores e, mais especificamente, em: brancos, índios, negros, mestiços e, posteriormente, em amarelos, tomando como base de classificação o sujeito brancomasculino-heterossexual-cristão-militar (SANTOS; SILVA, 20।8). Essa cisão entre raça superior e raças inferiores foi "necessária para separar dentro do projeto da Modernidade os "outros", aqueles que teriam suas histórias apagadas, aqueles que não são capazes de ser porque não são capazes de pensar" (FERREIRA; SILVA, 2019, p. 132).

Os povos originários e os escravizados do continente Africano foram submetidos à métrica eurocêntrica de ser, de pensar e de produzir conhecimentos; por não se enquadrarem nessa métrica foram classificados como não humanos, portanto, incapazes de ser, de pensar e de produzir conhecimento. Essa cisão reverbera nos currículos escolares "por isso a história e a cultura dos negros no Brasil no currículo escolar, por exemplo, tem se limitado muitas vezes a história e a cultura dos escravos, reduzindo os negros a essa condição" (SILVA, 20I5, p. 50).

Os territórios também foram racializados, pois seguiam a mesma lógica de racialização dos sujeitos uma vez que povos inferiores também habitavam territórios inferiores. Essa relação é evidenciada nas pesquisas de Silva, Torres e Lemos (2012) ao destacarem que os povos do campo ainda enfrentam hierarquizações pautadas na racialização da sociedade, visto que a herança legada do colonialismo localiza os sujeitos-povos em dois polos de localização. $\bigcirc$ primeiro polo (cidade) em que são considerados os sujeitos de cultura e de referência, esses sujeitos assumem, geralmente, funções relevantes na sociedade, 
constituindo-se enquanto lugar-tempo de referência. $\bigcirc$ segundo polo (campo) em que os sujeitos-povos não possuem cultura reconhecida, não podendo ser lugar-tempo de referência, consistindo majoritariamente no lugar da subalternidade.

colonialismo se consolidou como padrão de referência para todos esses povos tidos como inferiores, assim, suscetíveis de dominação e aceitação das imposições postas pelas nações julgadas como superiores, portanto, autoproclamadas proprietárias não só das terras descobertas, mas também de todos os seres que as habitavam.

Segundo Lopes e Macedo (20 I I), o colonialismo move-se restringindo diferentes formas de ser, de pensar, de construir conhecimento de uma única forma, tolhendo significações e representações outras que extrapolem os limites fixados pela razão moderna/eurocêntrica. É isso que o colonialismo tenta realizar quando, arbitrariamente, substitui os idiomas/ínguas dos povos originários pelo idioma do colonizador.

A cegueira para as cosmovisões outras, a nosso ver, é uma ofensiva e uma defesa pela preservação e difusão do cânone eurocêntrico. Ofensiva no sentido de que é preciso suprimir qualquer forma de ser, de pensar e de dizer que não esteja ancorada no cânone eurocêntrico - isto é, no paradigma simplificador (MORIN, 2005) que realiza uma assepsia epistemológica buscando uma suposta neutralidade - e que ameace a pretensa universalidade do referido cânone. É uma defesa, pois para se colocar como único é necessário que o outro seja vigiado, controlado, moldado, subalternizado e passe a acreditar que são inferiores, em vista disso precisam ser salvos por meio de processos educativos pautados em uma educação bancária (FREIRE, 1987), leia-se educação colonizadora, que entende os estudantes enquanto depósitos vazios, desprovidos de qualquer conhecimento, experiências sociais, culturais e políticas que mereçam ser consideradas.

Nessa perspectiva de educação, a seleção de conhecimentos garante o lugar hegemônico da matriz eurocentrada na sociedade, por meio de práticas que favorecem "a transmissão de saberes propedêuticos que são "depositados" no outro, colonizando-o, subalternizando-o, oprimindo-o" (FERREIRA; SILVA, 2013, p. 28).

Ao compreender essas relações de hierarquização e subalternização dos sujeitos outros, a teoria pós-colonial traz à baila a violência física, epistêmica, política e cultural imposta pelos colonizadores europeus aos povos originários e aos povos afro-diaspóricos escravizados. Para a teoria pós-colonial, essas relações de poder desiguais estabelecidas no período colonial permanecem sustentando o ideário colonial, mesmo após o fim das colônias e um dos meios de sua conservação é a educação escolar via, particularmente, currículos legitimados pelas avaliações externas estandardizadas. As avaliações externas homogeneizadoras tendem a legitimar os conhecimentos tidos verdadeiros (fundados na ciência moderna) em detrimento dos conhecimentos outros (que tomam por referência outras racionalidades) tidos como 
não conhecimentos, como é o caso dos conhecimentos dos povos indígenas, dos afro-brasileiros e africanos, dos ciganos, dos camponeses, das mulheres, etc.

Seguindo esta linha de raciocínio, o currículo pós-colonial busca descortinar as heranças coloniais (FERREIRA; SILVA, 20I3) que permanecem celebrando a soberania eurocêntrica, "isto é, saber em que medida o currículo contemporâneo, apesar de todas as suas transformações e metamorfoses, é ainda moldado pela herança epistemológica da colonização; e as formas de análises que concebem o processo de dominação cultural como via de 'mão única'” (CARVALHO, 2004, p. 44). Logo, os processos avaliativos tendem a validar os conhecimentos balizados nas heranças coloniais, decorrendo na negação dos sujeitos outros, pois

estes sujeitos o que primeiro aprendem na escola é que não-são, por isso que o currículo e a avaliação escolar não selecionam e nem validam suas culturas, e quando trazem algum elemento da cultura dos subalternizados, o fazem por dentro de uma hierarquização em que a cultura do branco eurocentrado sempre ocupa o lugar-tempo de referência tanto no currículo como na avaliação escolar (SILVA, 20 I 5, p. 15).

Nessa direção, os processos educativos balizados pelos preceitos do colonialismo se organizam em volta de um currículo monocultural, racista, patriarcal, sexista, classista, homofóbico, posto que esses elementos são constitutivos do paradigma eurocêntrico. Esse paradigma sustenta-se na falácia da universalidade e da neutralidade científica para justificar hierarquizações de gênero, de raça, de etnia, de territórios, de conhecimentos e de sexualidade. Segundo Silva,

nessa lógica, são instituídos os sujeitos curriculares: aqueles(as) que têm os elementos de suas culturas selecionados e validados no currículo e na avaliação escolar. Como também é imposto os sujeitos não curriculares, aqueles(as) que, ao não terem suas culturas reconhecidas, são culturalmente alienígenas no currículo e na avaliação escolar que se torna para eles(as) alienantes (2015, p. 5I).

Assim, o enfoque do currículo colonizador (tradicional) é a manutenção e a ocultação dos privilégios do cânone eurocêntrico para cultivar a sua existência, camuflando os privilégios históricos da branquetude. Seguindo essa linha de pensamento, há uma relação de poder que se retroalimenta por meio de negações, subalternizações, na medida em que é preciso negar a existência do diferente ao mesmo tempo em que é necessário afirmá-la, mas em um lugar inferior.

Segundo Santomé (2013), os sistemas de educação que tomam o padrão de sociedade monocultural se utilizam da estratégia de omissão para silenciar todas as demais realidades. Em determinados momentos, quiçá, fale-se dos outros, geralmente, para emudecê-los, negando-lhes a fala e, frequentemente, representando-os de acordo como os grupos hegemônicos da sociedade os inventam.

A contradição do poder colonial se assenta na dependência de reconhecimento do outro para que seja assegurado o seu poderio, ou seja, o poder colonial só existe tendo em vista que inventou o outro como inferior e, por tal inferioridade, suscetível à dominação. Por conseguinte, o aniquilamento do outro 
impossibilita a dominação colonial (LOPES; MACEDO, 20I I). Ainda que se apresente enquanto soberano, o poderio colonial é restrito, pois depende da existência do outro para se consolidar enquanto tal.

Não obstante, percebemos que essa relação de dependência é ofuscada na tentativa de não transparecer a fragilidade do poder colonial. Nessa busca por sobrevivência são abertas frestas de negociações entre o opressor colonizador e os colonizados. As negociações acontecem em circunstâncias óbvias de desigualdades, mas que revelam limitações no padrão mundial de poder colonial, mostrando a impossibilidade de cristalização e de homogeneização. Desse modo, há sempre lugar para o híbrido, para a emergência de significados outros que não são definidos e regulados pelo poder colonial.

Dessa maneira, o pensamento de fronteira produzido nessas tensões entre o poder colonizador e a resistências dos subalternizados que constroem conhecimentos outros não previstos pelo cânone eurocêntrico, gestando uma ecologia de saberes, ou seja, "um conjunto de epistemologias que partem da possibilidade da diversidade e da globalização contra-hegemônicas e pretendem contribuir para as credibilizar e fortalecer" (SANTOS, 2010b, p. I54). A referência para a construção de currículos outros sustenta-se nos conhecimentos dos sujeitos outros, entre tensões e conflitos com o conhecimento eurocêntrico.

Nesse sentido, a teoria pós-colonialista de currículo vai de encontro aos princípios do colonialismo, na medida em que pretende analisar as complexas relações de poder entre nações que constituem o legado econômico, político e cultural da conquista colonial europeia. $\bigcirc$ currículo pós-colonial realiza dois movimentos simultâneos: a) o primeiro desvela as heranças coloniais que ainda sobrevivem na atualidade e estão presentes nos currículos escolares; e, b) o segundo assinala para as possibilidades de rupturas com os currículos colonizados e para a construção de currículos descolonizados, por conseguinte, as práticas docentes são relevantes tanto na construção desses currículos, quanto para a materialização deles.

Em vista disso, o currículo pós-colonial ultrapassa a mera integração e oficialização da diferença nas determinações curriculares, ou seja, não se funda na interculturalidade funcional (WALSH, 2008) que visa apenas reconhecer as diferenças para integrá-las ao currículo sem que as hierarquizações sociais, epistemológicas, culturais sejam reveladas e questionadas e, menos ainda, rompidas.

Esse currículo contempla formas outras de produzir conhecimentos, pois funda-se na interculturalidade crítica (WALSH, 2008), em outros termos, revela as hierarquias epistemológicas, sociais, culturais, raciais, étnicas, territoriais, sexuais, de gênero, etc. ao revelar questiona-as e materializa diálogos conflitivos vis-à-vis com o cânone eurocêntrico. Na compreensão de Silva, Sartore e Santos (20। 9, p. 8) "a perspectiva de interculturalidade crítica busca elucidar as relações sociais desiguais a fim de contribuir para um processo de transformação social que enalteça vozes outras".

Além de elucidar tais relações, reivindicadas pela interculturalidade crítica, Almeida (20।7) defende a ideia do desenvolvimento da interepistemologia. Isto é, da superação da interculturalidade funcional e 
crítica, visto que ela implica não só em incluir as culturas dos povos tidos inferiores e estabelecer diálogos conflitivos, a fim de romper com o eurocentrismo nos currículos, mas também de incluir e estabelecer diálogos conflitivos entre epistemologias outras nos currículos.

Para tanto, urge a necessidade de questionar:

[...] em que medida as definições de nacionalidade e "raça", forjadas no contexto da conquista e expansão colonial, continuam predominantes nos mecanismos de formação de identidade cultural e da subjetividade embutidos no currículo oficial? De que forma as narrativas que constituem o núcleo do currículo contemporâneo continuam celebrando a soberania do sujeito imperial europeu? Como é que nessas narrativas são construídas as concepções sobre "raça", gênero e sexualidade que se combinam para marginalizar identidades que não se conformam com as definições da identidade considerada normal? (SILVA, 20।0, p. 129).

Diante desses questionamentos, cabe indagarmos em que medida as práticas docentes ainda celebram o sujeito branco-heterossexual-patriarcal-racista-classista, por estarem pautadas no currículo colonizado e colonizador? De que forma os conhecimentos eurocêntricos ainda hierarquizam e subalternizam conhecimentos outros, tais como os dos povos indígenas, da população negra, dos povos do campo, dos povos ciganos, etc.? Quais conteúdos celebram a racionalidade e a cosmovisão eurocêntrica em detrimento de outras racionalidades e cosmovisões? De que maneira as práticas docentes subvertem os currículos colonizados e colonizadores? Quais elementos são representativos de rupturas com esses currículos? Quais características que indicam a construções de currículos descolonizados? Quais epistemologias outras fundamentam as práticas descoloniais?

Embora não seja nossa intenção responder a todas essas indagações, consideramo-las pertinentes para ampliar as problematizações acerca de construção de currículos e de práticas docentes descoloniais. Dessa forma, essas indagações caminham na direção de apreender os movimentos de rupturas, proposições e materialização de currículos descolonizados, ou seja, de descolonização dos currículos, para isso Gomes defende que

[...] a descolonização do currículo implica conflito, confronto, negociações e produz algo novo. Ela se insere em outros processos de descolonização maiores e mais profundos, ou seja, do poder e do saber. Estamos diante de confrontos entre distintas experiências históricas, econômicas e visões de mundo. Nesse processo, a superação da perspectiva eurocêntrica de conhecimento e do mundo torna-se um desafio para a escola, os educadores e as educadoras, o currículo e a formação docente (2012, p. 107).

Compreendemos que a descolonização dos currículos faz parte de um processo mais amplo de enfrentamentos e negociações nos distintos espaços-tempos de disputas epistêmicas, sociais, culturais, políticas. Para Ferreira e Silva (2019), tanto as teorias curriculares quanto os currículos são espaço-tempo da diferença colonial, visto que "se radicalizou a consciência dos direitos entre aquelas/es que foram marcadas/os pela ferida colonial como inferiores, subalternos, selvagens, pobres, atrasados e, na escola, como defasados, repetentes, indisciplinados etc." (FERREIRA; SILVA, 2019, p. 133) essa tomada de consciência cria possibilidades de descolonização dos currículos e de construção de currículos outros. 
A descolonização dos currículos acontece na relação entre o macro e os micros espaços de poder, visto que um não se movimenta sem o outro. $\bigcirc$ macro constitui os lugares e os grupos sociais que pleiteiam e produzem significados em torno do currículo, como, por exemplo, os grupos hegemônicos que estão em constantes disputas com os grupos tidos como minorias sociais, principalmente "os Movimentos Negros e os Movimentos Feministas, em âmbito mais global, e os movimentos de resistência dos Zapatistas no México, dos indígenas no Equador, do Movimento dos Trabalhadores Sem Terra no Brasil, dentre tantos outros" (TORRES; SILVA, 2013, p. 139). Essas disputam, geralmente, são pela retirada, permanência e inserção de conhecimentos que constituem os currículos e que afetam, de forma direta e/ou indireta, determinadas concepções de cultural, sociedade, de sujeitos, etc.

O micro espaço de poder corresponde ao que acontece nos cotidianos dos sujeitos destinatários das políticas educacionais, dentre elas as de currículo. Entendemos que esses processos não ocorrem de forma indissociada, pelo contrário há uma correlação de forças que refletem os interesses dos grupos sociais, nem sempre de maneira equilibrada. Por conseguinte, as políticas educacionais que tratam especificamente de grupos subalternizados, em especial, pessoas negras, povos indígenas, mulheres etc., são resultado das lutas travadas por esses grupos e pelos grupos hegemônicos, provocando avanços nos textos legislativos. Por exemplo, as leis 10.639/2003 e । I.645/2008 que modificam a Lei de Diretrizes e Base da Educação (LDB) 9.394/l996 ao tornar obrigatória a inserção, nos currículos das instituições de ensino oficiais e privadas, do ensino da história e cultura afro-brasileira e indígena.

Sublinhamos que, apesar dessas Leis possuírem o intuito de viabilizar à justiça social para esses grupos, a sua inserção nos currículos escolares não garante a sua materialização nas práticas desenvolvidas nas escolas de forma efetiva, pois nas escolas coexistem forças coloniais e descolonias (SILVA, 20 I 5).

Nessa direção, ao nosso modo de ver, a formação de professores/as é de suma importância para o desenvolvimento de práticas docentes descoloniais, visto que, provavelmente, as suas formações também estiveram marcadas por um currículo da formação inicial colonizado. As supracitadas leis tiveram vetada a formação dos/as professores/as, considerada uma perda considerável para a luta dos sujeitos subalternizados. Esse veto foi/é um agravante para que os/as professores/as não se apropriem da discussão na perspectiva dos sujeitos outros e, até mesmo, para tomarem consciência da existência dessas leis, conforme aponta Ferreira (20|3).

Mesmo com esse veto, compreendemos que é possível o desenvolvimento de currículos e práticas docentes descolonizadas, em virtude de que foram as lutas dos movimentos sociais, sobretudo, negros e indígenas que pressionaram para que essas leis, e tantas outras, fossem sancionadas. Além disso, não podemos esquecer que os/as docentes também carregam as heranças coloniais presentes na sua pertença racial, étnica, de gênero, de classe social, de território, de sexualidade. No entanto, é premente que os/as 
docentes desvelem e questionem os lugares e tempos que ocupam nas políticas educacionais curriculares e na materialização delas.

Para tanto, o conceito de identidade na política ${ }^{2}$ se faz de suma importância para desvendar as amarras imperialistas presentes tanto nas políticas quanto nas práticas curriculares e docentes. $\mathrm{Na}$ identidade na política são os sujeitos outros que dizem suas identidades e as políticas são construídas fundamentadas nessas identidades, antes ofuscadas pelo controle da política de identidade. São os sujeitos outros que se dizem a partir e por meio de suas experiências individuais e coletivas.

A identidade na política rompe com a política de identidade imperialista que reduziu os povos originários e os advindos da África em dois grupos: índios e negros, negando e silenciando suas identidades. Por isso é que "o controle da política de identidade reside, principalmente, na construção de uma identidade que não se parece como tal, mas como a aparência "natural" do mundo" (MIGNOLO, 2008, p. 289) do mundo do colonizador. Dessa forma, "nos desvencilhamos da alegoria da política neutra, comprometida com a igualdade e com a inclusão, configurando-se enquanto adaptação criativa emancipadora, plural, coletiva, heterogênea, utópica" (TORRES, 2018, p. 104).

As conquistas dos movimentos negros, indígenas, entre outros, não se dão apenas no âmbito legislativo, mas também na luta cotidiana nas comunidades, nas escolas, nos sindicatos e associações de moradores, etc. pautados na identidade na política. Em vista disso, concordamos com Silva quando destaca que na

na mesma escola há forças Decoloniais que, ao longo do tempo, vêm se estruturando e evidenciando as contradições da Colonialidade. Exemplos das resistências e das proposições (Decolonialidades) são: a luta pela educação das relações étnico-raciais que tem se intensificado nos últimos anos; a luta dos indígenas e dos povos do campo por uma educação específica e diferenciada, entre outras (2015, p.57).

Desse modo, evidenciamos que essas lutas apresentadas pelo autor se aproximam da luta por uma educação intercultural crítica (WALSH, 2008), enquanto paradigma educativo outro, concretiza-se na feitura do fazer pedagógico vivenciado por meio das práxis política, epistêmica e contra-hegemônica questionadoras da colonialidade.

A educação intercultural crítica, a nosso ver, conduz à pedagogia descolonial, uma vez que essa pedagogia "é a força que questiona a forma como a colonialidade se estabelece em seus vários eixos e vias de materialidade, inclusive na constituição dos currículos colonizados/colonizadores" (FERREIRA; SILVA, 2018, p. 106). Em vista disso, a pedagogia descolonial é orientada pelas práxis das lutas dos povos subalternizados que dialogam com suas bases políticas e culturais na construção de currículos outros e, consequentemente, em práticas docentes outras em constante confronto com o poder eurocêntrico

\footnotetext{
${ }^{2}$ Conforme Mignolo (2008, p. 287), "é um movimento necessário de pensamento e ação no sentido de romper as grades da moderna teoria política (na Europa desde Maquiavel), que é _ mesmo que não se perceba _ racista e patriarcal por negar o agenciamento político às pessoas classificadas como inferiores (em termos de gênero, raça, sexualidade, etc)".
} 
(OLIVEIRA; CANDAU, 20 I0). Nesses termos, entendemos que a pedagogia descolonial é questionadora e propositiva, agindo simultaneamente no desvendamento das amarras imperiais herdadas do processo civilizatório colonial e na construção de uma pedagogia outra, que oriente práticas docentes outras, ou seja, descoloniais.

Nesse sentido, as práticas docentes, para além da corporificação dos currículos, são relevantes para a superação de currículos colonizadores e para a materialização de currículos outros em consonância com os projetos de vida dos sujeitos. Na próxima seção, apresentamos possíveis bases para a construção de práticas docentes descoloniais.

\section{PRÁTICAS DOCENTES DESCOLONIAIS: POSSÍVEIS CAMINHOS}

Esta seção aborda a discussão sobre práticas docentes descoloniais, de forma sintética, apresentamos o conceito de prática docente e, especificamente, aquele de prática docente descolonial. Discutimos, ainda, as articulações entre prática curricular e prática docente e, por fim, indicamos caminhos possíveis na construção de práticas docentes descoloniais. Cabe destacar que não existe uma única forma de prática docente descolonial; ela se apresenta conforme as especificidades dos sujeitos e dos contextos materiais a que pertencem.

Para cumprir com essa empreitada, pautamo-nos na perspectiva teórica de currículo pós-colonial, em virtude de que percebemos a impossibilidade de compreender as práticas docentes como "inocentes", alheias aos processos de silenciamento e subalternização dos sujeitos outros, de seus conhecimentos e de suas culturas legitimadas pelos currículos prescritos e reais.

Nessa esteira de pensamento, compreendemos que o currículo é uma construção social, pois o momento de construção da política curricular não se dissocia da prática. Segundo Goodson ( 1999, p. 67), o currículo opera em dois níveis "primeiramente em nível da própria prescrição, mas, também, em nível de processo e prática". Nessa perspectiva, o currículo, como prescrição, apresenta um roteiro a ser seguido pelos professores/as a fim de promover a materialização do que foi selecionado e estabelecido nos currículos. Esse roteiro, a nosso ver, revela hierarquizações e classificações que determinados conhecimentos possuem, mas também revela lutas e resistências em defesa de conhecimentos tidos enquanto não conhecimentos como, por exemplo, aqueles dos povos afro-brasileiros e indígenas. Enquanto que o currículo real descobre conhecimentos e práticas outras de produção de conhecimentos, quer dizer do que foi estabelecido e escrito no currículo prescrito, ainda há seleções de conhecimento até sua efetivação na prática docente.

Mesmo com a tentativa de regulação e controle presente nos currículos prescritos, são os/as professores/as um dos principais autores e atores do desenvolvimento curricular, pois ao modelarem o 
currículo, acabam por tomar decisões frente às políticas educacionais e determinações legais. Nessa perspectiva, a prática docente não é vista de forma simplista, como quer os currículos colonizados (tradicionais) que miram os docentes apenas como executores dos currículos, mas como um campo fértil de possibilidades outras de rupturas com currículos colonizados e colonizadores.

A prática docente, por sua vez, não se dá de forma individualizada, apartada das disputas e tensões dos contextos macro e micro. Ela faz parte do que Souza (20 I 2) nomeou de prática pedagógica constituída da prática docente, da prática discente, da prática gestora, da prática epistemológica. Por isso, a prática docente se articula de forma dialética ao todo (prática pedagógica) e as suas partes.

Nesse raciocínio, as práticas docentes são influenciadas pelas demandas externas que podem levar a metamorfoses internas. Conforme Franco (2012, p. 159), "pelas práticas pedagógicas, as práticas docentes podem ser transformadas, para melhor ou para pior. A sala de aula organiza-se pela teia de práticas pedagógicas que a envolve e com ela dialoga".

Desse modo, as práticas docentes são espaço-tempo privilegiado de recontextualizações e materialização dos currículos, ou seja, "momento em que alunos e professores vivenciam experiências nas quais constroem e reconstroem conhecimentos e saberes" (MOREIRA, 1998, p. 22). A construção e reconstrução de conhecimento e saberes passam inevitavelmente por seleções culturais daqueles conhecimentos dignos de serem ensinados e aprendidos.

Na teoria pós-colonial de currículo, esta hierarquização entre conhecimentos dignos de ser ensinados e não dignos é dissolvida, pois para essa teoria não existe um conhecimento digno ou indigno todos são importantes e cada um ganhará maior ou menor ênfase a depender dos interesses dos sujeitos e do contexto em que estão inseridos, de acordo com Freire (1987, p.68), "não há saber mais, nem saber menos, há saberes diferentes".

Logo, as práticas docentes se tornam complexas por se relacionarem a fazeres e a saberes que, ocasionalmente, constituirão uma totalidade harmoniosa. Da mesma forma, as propostas curriculares formais, que são direcionadas às escolas, são construídas no interior das mesmas contradições, admitindo uma maneira mais ou menos regulatória ou emancipatória em suas distintas proposições.

Oliveira (2003) destaca que, no cotidiano, o currículo é desenvolvido por meio de atividades que mesclam elementos das propostas formais curriculares (BNCC, livros didáticos, manual do/a professor/a) com as possibilidades de sua implementação no contexto social, cultural, político da escola. Essas possibilidades são tensionadas cotidianamente pelos sujeitos que compõem a comunidade escolar, mas também pelos sujeitos que na esfera macro (porexemplo: as secretarias de educação dos estados e dos municípios) determinam o que é currículo, de que forma ele deve ser desenvolvido e com quais materiais.

Segundo Oliveira (2003, p. 82), "é nesse sentido que entendemos práticas curriculares cotidianas como "multicoloridas", pois suas tonalidades vão depender sempre das possibilidades daqueles que as 
realizam e das circunstâncias nas quais estão envolvidos". Dessa forma, as práticas docentes descoloniais também são "multicoloridas", haja vista que abraçam os diferentes conhecimentos dos sujeitos que fazem parte da escola. Esses conhecimentos possuem cores e tons diferenciados, logo podem compor um arcoíris que contrasta com uma perspectiva de currículo e práticas curriculares e docentes monocromáticas.

Parece-nos que esse é ainda um grande desafio para os docentes e para os sujeitos (estudantes, gestores/as, coordenadores/as, merendeiras, etc.) que constituem as instituições escolares loci privilegiados de materialização e recontextualizações curriculares, bem como para os formuladores das políticas curriculares. A exemplo da Base Nacional Comum Curricular forjada através de uma parca participação dos sujeitos que compõe as instituições escolares, revelando a sua filiação à herança colonial, ou seja, à colonialidade (QUIJANO, 2005).

A presença da colonialidade nos lugares e tempos de decisão curricular ainda influencia à construção e reconstrução dos conhecimentos e dos saberes nas práticas docentes, gestando um campo de tensões entre o que é estabelecido pelas prescrições curriculares fora do ambiente escolar e o que é recontextualizado nas escolas por seus sujeitos praticantes (CERTEAU, 20|4) do currículo, de maneira especial, professores/as.

Com base nesse pensamento, para que seja possível a materialização de práticas docentes descoloniais é necessário que os sujeitos participantes sejam considerados como detentores de conhecimentos que se organizam de distintas formas o que não os tornam inferiores, em nenhum aspecto, por não tomar por referência o cânone eurocêntrico de produção de conhecimento.

Os indícios de descolonização das práticas docentes, a nosso ver, são influenciados pelas lutas sociais dos sujeitos que, historicamente, foram/são subalternizados por pertencerem a determinado gênero e/ou raça, etnia, território, classe social, etc. Descolonizar as práticas docentes compreende um processo amplificado, isto é, descolonizar os conhecimentos negados e subalternizados pela colonialidade do saber (QUIJANO, 2005) que classificou e hierarquizou os conhecimentos dos sujeitos subalternizados historicamente vistos como desprovidos de conhecimentos, ocorrendo na inviabilização dos conhecimentos outros.

As pesquisas de Silva, Ferreira e Silva (20 I3), sobre a temática da Educação para as relações Étnicoraciais, evidenciam a necessidade de questionar o conhecimento de referência que constitui o currículo, mas também quais os conhecimentos negados e quais as consequências maléficas dessa negação no currículo, na educação como um todo, em especial, nas práticas docentes, e para a sociedade de modo geral.

Destacamos a importância da formação inicial e continuada dos professores/as para a transformação da consciência ingênua em consciência crítica (FREIRE, 1967), possibilitando ressoar no desenvolvimento de práticas curriculares e docentes descoloniais, uma vez que, em sua maioria, os 
currículos dos cursos de formação de professores/as ainda continuam colonizados e colonizadores. Desse modo, construir espaços outros de formação, que busquem romper com o ideário colonial ainda presente, torna-se de suma importância.

Por exemplo, quando pensamos os/as professores/as enquanto decisores curriculares (LEITE, 2006) significa dizer que são esses sujeitos que elegem e reinterpretam os sentidos dos textos políticos que melhor condizem com seus anseios, pessoais e profissionais. Seguindo essa linha de raciocínio, a formação de professores e o desenvolvimento da profissionalidade docente são peças-chaves para que professores atuem como decisores curriculares. Nóvoa (2017) evidencia que a formação de professores tem sofrido com as investidas neoliberais que acentuam políticas de privatização e de desprofissionalização docente.

Apesar dos esforços de desprofissionalização docente, os professores, enquanto decisores curriculares rompem com a ideia de sujeitos acomodados, inertes às determinações das políticas educacionais, especificamente as de currículo. Também revelam as complexas relações que são estabelecidas tanto no âmbito da formulação de políticas educacionais mais amplas que reverberam, notadamente, na política de formação de professores, quanto no nível de atuação dos sujeitos nos cotidianos escolares, por meio das políticas curriculares.

Do nosso ponto de vista, a finalidade da prática docente descolonial segue três caminhos que se entrelaçam, a saber: I) desvelamento das marcas da colonialidade presentes nos currículos prescritos, praticados e nos materiais curriculares didáticos pedagógicos, entre eles, os livros didáticos que, muitas vezes, se tornam o próprio currículo das escolas; 2) proposição e construção de currículos outros alicerçados nos contextos sociais, culturais, políticos e territoriais dos sujeitos; 3) construção coletiva de práticas docentes descoloniais que não neguem suas contradições, mas que se aprenda a reduzi-las, ao máximo, para que cada vez mais sejam consolidadas práticas docentes coerentes, gestando culturas escolares outras, mais equitativas, quiçá, descoloniais em sua totalidade.

\section{CONSIDERAÇÕES FINAIS}

Nosso objetivo, com este texto, centrou-se em entender as práticas docentes enquanto um dos espaços-tempo de possibilidades de descolonização dos currículos. Nesse sentido, destacamos a importância da adoção da perspectiva teórica do currículo pós-colonial enquanto possibilidade de rupturas com os currículos colonizadores (tradicional).

Ao lançarmos um olhar investigativo para a construção de currículos descoloniais, compreendemos que o currículo prescrito e praticado é resultado das disputas que permeiam o campo do currículo. Essas 
disputas são tensionadas tanto pelos espaços macro de produção do currículo quanto pelos os espaços micro de produção e materialização curricular, em constante diálogo.

Diante do apresentado, concluímos que práticas docentes descoloniais são possíveis através de dois movimentos, são eles: desvendar as marcas do colonialismo nos currículos e construir práticas outras que rompam com o cânone eurocêntrico valorizando os conhecimentos dos sujeitos que, historicamente, foram silenciados e negados pelo referido cânone. Para tanto, a identidade na política nos parece essencial para a construção de currículos ancorados pelos anseios dos sujeitos outros, visto que rompe com a política de identidade imperialista que ainda se apresenta como hegemônica tanto nas políticas curriculares, quanto nas práticas desenvolvidas por docentes.

Destacamos a urgência de se pensar na construção e desenvolvimento de currículos pós-coloniais enquanto uma teoria-prática outra que, para além de desvelar as amarras imperiais, compromete-se com a constituição de currículos descolonizados. Descolonizar os currículos implica em rememorar os conhecimentos, as culturas dos diferentes povos que habitaram/habitam a os territórios colonizados pela matriz colonial eurocêntrica e norte americana, localizando-os nos currículos escolares de forma equitativa, estabelecendo diálogos interculturais pautados na justiça social e na interepistemologia.

Em outras palavras, descolonizar os currículos não se restringe, unicamente, à prática de inserções cotidianas, no chão das escolas, das culturas negadas (SANTOMÉ, 20I3), mas necessita, também, fazer parte de uma mudança de paradigma epistemológico. Ou seja, de um giro descolonial das epistemologias que sustentam as políticas educacionais e, principalmente, aquelas de currículo e de avaliação, tendo em vista a relação intrínseca entre elas. No entanto, entendemos que isso não acontece de forma homogênea, pois as ambivalências e assimetrias são representativas dessa impossibilidade de homogeneização.

Logo, evidenciar a colonialidade do saber torna-se condição indispensável da teoria do currículo pós-colonial na denúncia e na busca pela superação das hierarquias fundamentadas na cosmovisão eurocêntrica, bem como propor formulação e concretização de currículos escolares afinados com as cosmovisões dos sujeitos outros que tiveram seus conhecimentos, suas culturas negadas e/ou subalternizadas nos currículos escolares fundados na monocultura e no conhecimento único sustentados pela colonialidade do saber, especialmente.

Nessa esteira de raciocínio, a formação inicial e continuada dos professores abre maiores possibilidades de construção de práticas docentes descoloniais, caso sua formação profissional e o desenvolvimento de sua profissionalidade estejam pautadas em um currículo da formação descolonial. Os professores/as, enquanto decisores/as curriculares, podem caminhar para práticas docentes descoloniais, visto que ter apenas a formação não garante sua efetivação, mas que esta é imprescindível para uma possível descolonização dos currículos e de suas práticas. 


\section{REFERÊNCIAS}

ALMEIDA, Eliene Amorim de. A Interculturalidade no Currículo da Formação de Professoras e Professores Indígenas no Programa de Educação Intercultural da UFPE/CAA - Curso de Licenciatura Intercultural, 2017. 225 f. Tese (Doutorado em Educação) - Universidade Federal de Pernambuco UFPE, Recife, 2017.

ALMEIDA, Eliene Amorim de; SILVA, Janssen Felipe da. Abya Yala Como Território Epistêmico:

Pensamento Decolonial Como Perspectiva Teórica. Revista Interritórios, Caruaru, v. I, n I, p. 42-64, 2015.

APPLE, Michael W. A luta pela democracia na educação crítica. Revista e-Curriculum, São Paulo, v. I5, n.4, p. 894 - 926 out./dez. 2017.

ARROYO, Miguel. Currículo, território em disputa. Petrópolis: Vozes, 2011 .

BALL, Stephen John. Diretrizes Políticas Globais e Relações Políticas Locais em Educação. Currículo sem Fronteiras, v. I, n.2, pp.99-। I6, Jul/Dez 2001.

BARDIN, Laurence. Análise de conteúdo. Lisboa: Edições 70, 201 I.

BERNSTEIN, Basil. A pedagogização do conhecimento: estudos sobre recontextualização. Cadernos de Pesquisa, São Paulo, n. 120, p. 75-1 10, 2003.

CARVALHO, Rosângela Tenório de. Discursos pela interculturalidade no campo curricular da educação de jovens e adultos no Brasil nos anos 1990. Recife: Bagaço, 2004.

CERTEAU, Michel de. A invenção do cotidiano: I. Artes de fazer. Petrópolis, RJ: Vozes, 20 I4.

FERREIRA, Michele Guerreiro, SILVA, Janssen Felipe da. Confluência entre a Pedagogia Decolonial e a Educação das Relações Étino-raciais: elementos de uma práxis curricular outra a partir das contribuições de Franz Fanon e Paulo Freire. In: GARCIA, Maria de Fátima; SILVA, José Antônio Novaes da. (Org.). Africanidades Afrobrasilidades e processo (des)colonizador: contribuições à implementação da Lei 10.639/03. João Pessoa: Editora UFPB, 2018.

FERREIRA, Michele Guerreiro, SILVA, Janssen Felipe da. Opção Decolonial e Práxis Curriculares de Enfrentamento do Racismo: diálogos com sujeitos curriculantes de licenciaturas da Universidade da Integração Internacional da Lusofonia Afro-Brasileira. Revista Interritórios, Caruaru, v. 5, n 8, p. I2 I - I 50, 2019.

FERREIRA, Michele Guerreiro. Sentidos da educação das relações étnico-raciais nas práticas curriculares de professores (a)s de escolas localizadas no meio rural. 2013. 179 f. Dissertação (Mestrado em Educação Contemporânea) Universidade Federal de Pernambuco - UFPE - Centro Acadêmico do Agreste - CAA, Caruaru, 2013.

FERREIRA, Michele Guerreiro; SILVA, Janssen Felipe da. Silva Perspectiva Pós-Colonial das Relações Étnico-Raciais nas Práticas Curriculares: conteúdos selecionados e silenciados. Revista Teias, Rio de Janeiro, v. 14, n. 33, p. 25-43, 2013.

FRANCO, Maria Amélia do Rosário Santoro. Pedagogia e prática docente. I. ed. São Paulo: Cortez, 2012. 
FREIRE, Paulo. A educação como prática da liberdade. Rio de Janeiro, RJ: Paz e Terra, 1967.

FREIRE, Paulo. Pedagogia do oprimido. $17^{\mathrm{a}}$ ed. Rio de Janeiro, Paz e Terra, 1987.

GOMES, Nilma Lino. Relações étnico-raciais, educação e descolonização dos currículos. Currículo sem Fronteiras, v. 12, n. I, p. 98-109, Jan/Abr 2012.

GOODSON, Ivor. Currículo: teoria e história. 3. ed. Petrópolis: Vozes, 1999.

HALL, Stuart. Da Diáspora: identidades e mediações culturais. Belo Horizonte: Editora da UFMG, 2003.

Imagens de mulheres negras e indígenas nos livros didáticos dos territórios campesinos brasileiro e colombiano. Roteiro, Joaçaba, v. 44, n. 2, p. I-32, maio/ago. 2019.

LEITE, Carlinda. Políticas de currículo em Portugal e (im)possibilidades da escola se assumir como uma instituição curricularmente inteligente. Currículo sem Fronteiras, v.6, n.2, p.67-8I, Jul/Dez 2006.

LOPES, Alice Casimiro. Teorias pós-críticas, política e currículo. Educação, Sociedade \& Culturas, Porto, n. 39, pp. 7-23, 2013.

LOPES, Alice Casimiro; MACEDO, Elizabeth. Teorias do currículo. São Paulo: Cortez, 201 I .

MIGNOLO, Walter. Historias locales/diseños globales: colonialidad, conocimientos subalternos y pensamientos fronterizo. Madrid: Akal, 2011 .

MOREIRA, Antônio Flávio Barbosa. Multiculturalismo, currículo e formação de professores. Anais do IX Endipe, Águas de Lindóia, SP, 1998.

MORIN, Edgar. Introdução ao pensamento complexo. Porto Alegre: Sulina, 2005.

NÓVOA, António. Firmar a posição como professor, afirmar a profissão docente, Cadernos de Pesquisa, v.47 n. 166 pp. I I06- II 33 out./dez, 2017.

OLIVEIRA, Inês Barbosa de. Currículos praticados: entre a regulação e a emancipação. Rio de Janeiro: DP\&A, 2003.

OLIVEIRA, Inês Barbosa de. Tendências recentes dos estudos e das práticas curriculares. In: VÓVIO, Cláudia Lemos; IRELAND, Timothy Denis. Construção coletiva: contribuições à educação de jovens e adultos. Brasília: UNESCO, MEC, RAAAB, 2005.

OLIVEIRA, Luiz Fernandes de; CANDAU, Vera Maria Ferrão. Pedagogia Decolonial e Educação Antirracista e intercultural no Brasil. Educação em Revista. Belo Horizonte, v. 26, n. 0 I , p. I5-40, abr. 2010.

QUIJANO, Aníbal. Colonialidade do Poder. In: LANDER, Edgar (Org.). A Colonialidade do Saber: eurocentrismo e Ciências sociais. Perspectivas latino-americanas. Colección Sur, CLACSO, Ciudad Autónoma de Buenos Aires, Argentina. Siembro, 2005.

SANTOMÉ, Jurjo Torres. Currículo escolar e justiça social: o cavalo de Troia da educação. Porto Alegre: Penso, 2013.

SANTOS, Aline Renata dos. Patriarcalização e despatriarcalização nas imagens de mulheres nos livros didáticos da educação do campo do Brasil e da Colômbia. 2017.224 f. Dissertação (Mestrado em Educação) - Universidade Federal de Pernambuco, Recife, 2017. 
SANTOS, Aline Renata dos. SILVA, Janssen Felipe da. Diálogo entre os estudos pós-coloniais e o feminismo latino-americano na compreensão do patriarcado na constituição da américa latina. REALIS, Recife, v.8, n. 01, p. I20-1 47 Jan-Jun. 2018.

SANTOS, Boaventura de Sousa. A Gramática do tempo: para uma nova cultura política. 3. ed. São Paulo: Cortez, 20IOb.

SANTOS, Boaventura de Sousa; MENESES, Maria Paula. Introdução. In: SANTOS, Boaventura de Sousa; MENESES, Maria Paula. (Org.). Epistemologias do Sul. São Paulo: Cortez, 2010 .

SANTOS, Boaventura de Souza. Para Além do pensamento abissal: das linhas globais a uma ecologia dos saberes. In: SANTOS, Boaventura de Souza; MENEZES, Maria Paula (Org.). Epistemologias do Sul. Coimbra, Portugal: Cortez Editora, 20 I0a. p. 3 I-83.

SARTORE, Anna Rita; SANTOS, Aline Renata dos; SILVA, Camila Ferreira da. Tecendo Fios Entre o Feminismo Latino-Americano Descolonial e os Estudos Pós-Coloniais Latino-Americanos. Revista Interritórios, Caruaru, v. I, n. I, 2015.

SILVA, Janssen Felipe da. Sentidos de Avaliação da Educação e no Ensino e no Currículo na Educação Básica através dos Estudos Pós-Coloniais Latino-americanos. Espaço do Currículo, João Pessoa, v.8, n. I, p.49-64, janeiro a abril de 2015.

SILVA, Janssen Felipe da; FERREIRA, Michele Guerreiro; SILVA, Delma Josefa da. Educação das relações Étnico-raciais: um caminho aberto para a construção da Educação Intercultural. Revista Eletrônica de Educação, São Carlos, v. 7, n. I, maio, 2013.

SILVA, Janssen Felipe da; SARTORE, Anna Rita; SANTOS, Aline Renata dos.

SILVA, Janssen Felipe da; TORRES, Denise Xavier; LEMOS, Girleide Torres. Educação do Campo: a luta dos Movimentos Sociais Campesinos Por uma Educação Escolar específica e diferenciada. Revista Pedagógica - UNOCHAPECÓ - Ano- 15 - n. 28 vol. 01 - jan./jun. 2012.

SILVA, Tomaz Tadeu da. Documentos de Identidade: uma introdução às teorias do currículo. Belo Horizonte: Autêntica, 2010.

SOUZA, João Francisco de. Prática pedagógica e formação de professores. Recife: Ed. Universitária da UFPE, 2012.

TORRES, Denise Xavier. Tensões entre Avaliações da aprendizagem, Avaliações de Sistema e Educação do Campo: a disputa nas fronteiras da validação de conhecimentos. 20 I 8. 300 f. Tese (Doutorado em Educação) - Universidade Federal de Pernambuco, Recife, 2018.

TORRES, Denise Xavier; SILVA, Janssen Felipe. Estudos pós-coloniais no Brasil: sujeitos, processos e proposições da trajetória de educação escolarizada ofertada aos povos campesinos no Brasil. In:

Observatorio Latinoamericano - Dossier Brasil Buenos Aires, v. I0, p. I35- I48, enero, 2013.

VALA, Jorge. A Análise de Conteúdo. In: SILVA, A. dos S.; PINTO, J. M. (Org.). Metodologia das Ciências Sociais. Porto: Edições Afrontamento, 1999.

WALSH, Catherine. Interculturalidad, plurinacionalidad y decolonialidad: las insurgências politicoepistémicas de refundar el Estado. Tabula Rasa, Bogotá, n. 9, 2008. 


\section{COMO CITAR ESSE ARTIGO}

\section{Associação Brasileira de Normas Técnicas (ABNT)}

SANTOS, Aline Renata dos; SILVA, Janssen Felipe da. Currículo pós-colonial e práticas docentes descoloniais: caminhos possíveis. Debates em Educação, Maceió, v. 12, p. 387-407, set. 2020. ISSN 2175-6600. Disponível em: https://www.seer.ufal.br/index.php/debateseducacao/article/view/9630. Acesso em: dd mmm. aaaa.

\section{American Psychological Association (APA)}

Santos, A., \& Silva, J. (2020). Currículo pós-colonial e práticas docentes descoloniais: caminhos possíveis. Debates em Educação, 12(Esp), 387-407. doi: https://doi.org/l0.28998/21756600.2020v12nEspp387-407 